\title{
Memorias de la zona tórrida: el naturalismo clásico y la «tropicalidad» americana en el Sumario de la natural historia de las Indias de Gonzalo Fernández de Oviedo (1526)
}

por

Nicolás Wey Gómez

Division of the Humanities and Social Sciences - California Institute of Technology

\begin{abstract}
Este ensayo examina el papel que juega la «tropicalidad» en la taxonomía de la naturaleza y cultura americanas que ofrece Oviedo en el Sumario de la natural historia de las Indias (1526). Accediendo a los paradigmas cientificos y técnicos que informan este tratado, se arguye que la construcción de las Indias como un lugar «tropical» distinto de la Europa mediterránea pero similar a las Indias Orientales, le sirve a Oviedo de un marco de referencia fundamental para representar la compleja otredad de lo americano y a la vez abordar un debate geopolitico sobre el derecho de la conquista.
\end{abstract}

Palabras clave: América; historia natural; etnografia; zoología; botánica; mineralogía; teoría de las cinco zonas; zona tórrida.

Este ensayo investiga los avatares del conocimiento natural y antropológico de la antigüedad en las letras de Gonzalo Fernández de Oviedo y Valdés (1478-1557), cuyo arte se forjó entre la magia de las novelas de caballería y la de las crónicas de Indias ${ }^{1}$. En el Sumario de la natural historia de las Indias, impreso en 1526, Oviedo le explica a Carlos V la dificultad que presenta clasificar el tigre manchado de la llamada Tierra Firme entre los grandes felinos como los leones, los tigres y las panteras. Oviedo rechaza el nombre de tigre de la India para referirse al animal que los indios conocían como

${ }^{1}$ Como se sabe, años antes de la publicación de su primera obra indianista, Oviedo fue autor del Libro del muy esforçado e invincible caballero de la fortuna propiamente llamado don Claribalte, impreso en Valencia en 1519. 


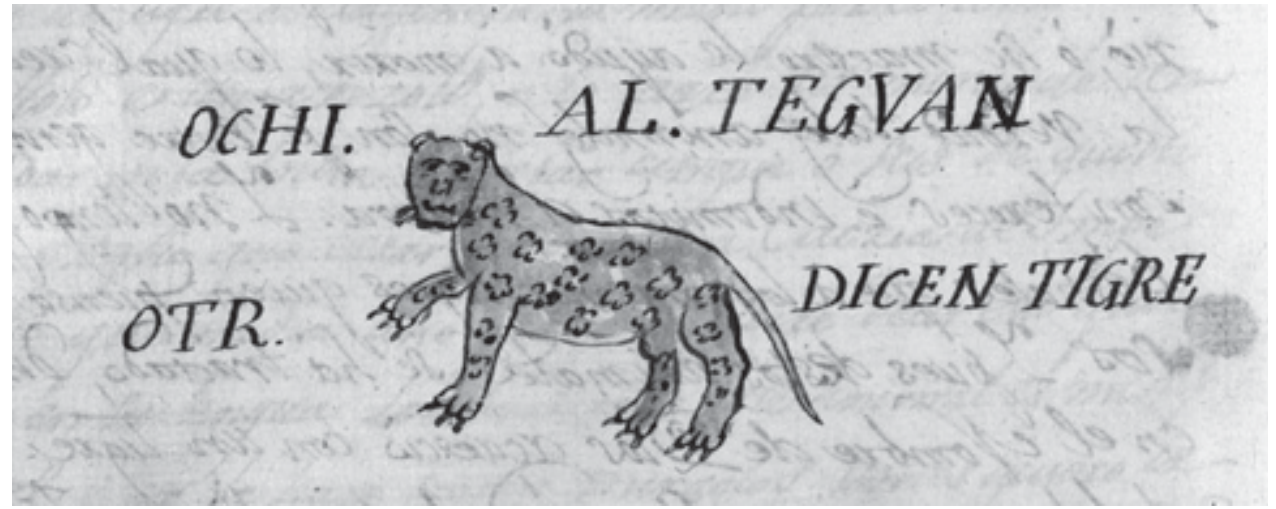

Reproducción del tigre manchado de Oviedo. El Sumario, impreso en 1526, incluye cuatro grabados basados en dibujos del autor, pero desafortunadamente ninguno de ellos incluye al jaguar. Oviedo más tarde copió y aumentó su capítulo sobre tigres para la extensa Historia general y natural de las Indias (Primera Parte, 1535). Al parecer, en el libro XII, capítulo 10 del manuscrito de esta obra (1548/1549), Oviedo incluyó un dibujo del jaguar que se encuentra perdido. La presente reproducción se supone fiel al original de Oviedo y fue realizada por Juan Bautista Muñoz en su copia de la Historia general (siglo XVIII). Cortesía del Archivo de la Real Academia de la Historia, Madrid, Muñoz A/35, folio 159 verso.

ochi y que hoy conocemos como el jaguar (fig. 1). Con todo lo majestuoso que pueda ser el jaguar, carece de la notoria «ligereza» que los geógrafos de la antigüedad, empezando por Plinio el Viejo, le asignaban a los tigres de la legendaria India ${ }^{2}$. En su Historia natural, Plinio afirmaba que los tigres de Bengala y los que habitaban la provincia de Hircania, en las inmediaciones de los montes Caspios, poseían velocitas tremenda ${ }^{3}$.

Aludiendo al vasto repertorio de maravillas naturales que proliferan en los confines de la tierra, Oviedo razona que el felino Americano no es el mismo felino descrito por Plinio: lo que Oviedo denomina «las diversidades de las provincias y constelaciones donde se crían [las criaturas]» supuestamente causa que cada criatura exhiba naturalezas más o menos extremas dependiendo de su hábitat natural ${ }^{4}$. Así pues,

2 Fernández de Oviedo, 2010/1526: 147-148. Sigo la edición de Álvaro Baraibar, cuyo estudio preliminar y notas proveen, por vez primera en una edición moderna, un contexto rico para la lectura del Sumario.

3 Plinio, 1938-1963, vol. 3: 50-51

${ }^{4}$ Fernández de Oviedo, 2010/1526: 148. 
vemos que las plantas que son nocivas en unas partes, son sanas y provechosas en otras, y las aves que en una provincia son de buen sabor, en otras partes no curan de ellas ni las comen; los hombres que en una parte son negros, en otras provincias son blanquísimos, y los unos y los otros son hombres: ya podría ser que los tigres asimismo fuesen en una parte ligeros, como escriben [Plinio y otros autores], y que en la India de vuestra majestad, de donde aquí se habla, fuesen torpes y pesados. Animosos son los hombres y de mucho atrevimiento en algunos reinos, y tímidos y cobardes naturalmente en otros.

Lo que Oviedo llama la «propia vista», elemento fundamental de la «experiencia», ya ha confirmado tales verdades en las Américas: por ejemplo, el zumo de una raíz autóctona como la yuca (o el casabe) se puede utilizar para envenenar flechas en la isla Española, mientras que se manifiesta totalmente inofensiva, incluso digestiva, más cerca del Ecuador, en las tierras firmes de Centro y Suramérica. Lo mismo parece ocurrir con animales de mayor envergadura geográfica: «Los murciélagos de España aunque piquen», advierte, «no matan ni son ponzoñosos, pero en Tierra Firme muchos hombres murieron de picaduras de ellos». Por lo tanto, se excusa Oviedo, «ni tengo ni dejo de tener por tigres estos tales animales, o por panteras o otro de aquellos que se escriben del número de los que se notan de piel maculada, o por ventura otro nuevo animal que asimismo la tiene y no está en el número de los que están escritos» ${ }^{5}$. Es más, continúa, la mayoría si no todos los animales que describe en su tratado habrían sido desconocidos para los antiguos por hallarse «en parte y tierra que hasta nuestros tiempos era incógnita, y de quien ninguna mención hacía la Cosmografia del Tolomeo ni otra, hasta que el almirante don Cristóbal Colón nos la enseñó»».

La negativa de Oviedo a identificar el jaguar con cualquiera de los grandes felinos conocidos en el Viejo Mundo se ha interpretado como una «crisis de representación» sintomática de la consciencia en Oviedo de que la nomenclatura y taxonomías tradicionales para describir la naturaleza se mostraban insuficientes para abarcar las particularidades naturales del Nuevo Mundo, consciencia que habría llevado a Oviedo a privilegiar su experiencia subjetiva de la naturaleza indiana como principio organizacional del Sumario ${ }^{6}$. No obstante, la utilidad de tal análisis para apreciar la recursividad del naturalismo clásico ante la realidad americana y la cuidadosa referencia de Oviedo a «las diversidades de las provincias y constelaciones donde se crían [las criaturas]» nos sugiere que el autor se hallaba muy lejos de cuestionar paradigmas

5 Ibidem: 149.

${ }^{6}$ Sobre el papel que la memoria y la subjetividad juegan en la organización de la materia indiana en el Sumario, ver Prieto, CXXIV/2 (New York, NY, 2009): 336-342. Sobre las razones que habrían llevado a Oviedo a rechazar el nombre de tigre de la India para el jaguar, ver el ensayo de Carrillo Castillo, XVI, 4 (Cambridge, UK, 2003): 497-498. 
científicos y técnicos que el occidente latino había asimilado de los griegos y árabes desde los siglos XII y XIII. Tales paradigmas por sí habrían dado lugar para explicar no sólo la enorme diversidad del mundo natural conocido por la Europa precolombina, sino también las inquietantes semejanzas y diferencias entre la naturaleza indiana y la del Viejo Mundo.

Me interesa examinar el papel que juega la «tropicalidad» en la taxonomía sin precedente que ofrece Oviedo de la naturaleza y cultura americanas. Subrayo aquí el debate geopolítico que, a mi parecer, impulsa el retrato que pinta Oviedo de los tigres, la yuca, los murciélagos y las gentes de América. Tal debate en última instancia concierne los títulos de conquista a las Indias y el estatuto legal del Indio en un naciente orden globalizador, la gran polémica que Rolena Adorno localiza al corazón de las letras americanas ${ }^{7}$.

De muchacho en la corte de Fernando e Isabel, Oviedo presenció en 1493 la triunfante vuelta de Colón de las tierras que inicialmente se identificaron con los confines orientales de la India ${ }^{8}$. A la muerte de su amo el infante Don Juan en 1497, Oviedo rodó varios años tras distintas faenas cortesanas en Italia, donde parece haber asimilado buena parte de la sensibilidad humanística que subyace de su obra ${ }^{9}$. Hacia 1512, radicado otra vez en España, donde incluso había llegado a ocuparse como escribano del Santo Oficio, Oviedo cometió el error de malgastar su magra hacienda en aderezarse como secretario del Gran Capitán Fernando González de Córdoba para una expedición contra los franceses que fue abortada antes de partir para Italia. Viéndose en la ruina, y acaso sin esperanza de hacerse a algún otro amo influyente de los que había aprendido a cultivar desde su adolescencia en la casa de los Reyes Católicos, Oviedo se vio forzado a probar nueva suerte en las Indias. Logró poco después hacerse nombrar miembro de la expedición de conquista que el infame Pedrarias Dávila dirigiera en 1514 contra el Darién, la región que hoy se extiende entre el Golfo de Urabá en Colombia y el Golfo de Panamá en el Pacífico.

A Oviedo le fueron otorgados distintos cargos durante su larga carrera indiana, entre ellos, inicialmente, el de veedor de las fundiciones de oro y el de escribano en la expedición de Pedrarias. Hacia 1519, presentando sus primeras quejas contra Pedrarias ante la corte, Oviedo tramitó pero desistió

\footnotetext{
7 Adorno, 2007: 1-20.

${ }^{8}$ Para un esbozo útil de la vida y obras de Oviedo, ver Myers, 2007: 12-25. Quizás la biografía más completa y juiciosa de Oviedo se encuentre en Ballesteros Gaibrois, 1981. He consultado también las biografías clásicas de Amador de los Ríos, 1851 y Juan Pérez de Tudela Bueso, 1991 [1959].

9 Sobre la vida de Oviedo en Italia, ver Gerbi, 1985: 145-200. Sobre la «biblioteca» de Oviedo, ver Turner, XXXI (Madrid, 1971).
} 
de la gobernación de Santa Marta (Colombia) por no conseguir que se le asignaran "cient hábitos de Sanctiago para cient hombres hijosdalgos» que le ayudasen a gobernar la zona ${ }^{10}$. Fue nombrado en cambio regidor perpetuo de la primera población europea en suelo continental, Santa María Antigua del Darién, reteniendo sus cargos como escribano y veedor de la región. $\mathrm{Su}$ ahora franco enemigo Pedrarias seguía en pie por la repentina muerte en 1520 del gobernador que la corona había enviado para reemplazarlo, y pronto trasladó operaciones al tanto más remoto Golfo de Panamá. Desde su nueva sede, Pedrarias fraguaría mantener a Oviedo bajo control otorgándole (y eventualmente restándole) la tenencia y capitanía de la gobernación que Pedrarias había abandonado al hambre, enfermedad y guerra civil en Urabá (1521 a 1522/1523). Escapando apenas con vida de los enemigos que le había traído el ejercicio un tanto voluntarioso de sus poderes en la turbulenta provincia, Oviedo inició una segunda ronda de gestiones ante la corte (15231526) que derivaría en la destitución definitiva de Pedrarias y en la obtención para sí mismo de la gobernación de Cartagena de Indias (Colombia). Pero de tránsito en Panamá, al enterarse de que Cartagena se hallaba arrasada por «indios bravos» hostigados por Rodrigo de Bastidas, el gobernador de Santa Marta, renunció a este cargo, sin haberlo ejercido, para retomar su oficio como veedor de las fundiciones de oro en Tierra Firme, oficio en que lo había de reemplazar su hijo Francisco en 1532. En aquel año, Oviedo sería nombrado cronista general de las Indias; en 1533, comandante de la guarnición del fuerte de Santo Domingo; y en 1549 regidor perpetuo de la misma ciudad, oficios todos que continuó desempeñando hasta el final de sus días.

Desde su primera estancia en el Darién, Oviedo parece haber hecho alarde de virtud denunciando la corrupción de colegas como Pedrarias; e indudablemente movido por el yugo de lealtad que lo habría marcado desde su formación como protegido de la familia real, Oviedo se pronunciaría siempre a favor de que la corona interviniese firmemente en la dispensa de justicia en las colonias. Oviedo incluso condenó a voz en cuello los abusos cometidos por sus coetáneos europeos en las regiones de Panamá, Colombia y Nicaragua. En el Sumario, por ejemplo, Oviedo se queja de aquellos cristianos que en la Tierra Firme habían cometido atrocidades «no de hombres, sino de dragones y de infieles pues sin tener respeto alguno de humano, han seido causa que muchos indios que se pudieran convertir y salvarse muriesen por diversas formas y maneras» ${ }^{11}$. Según Oviedo, el cínico concepto de pacificación que

${ }^{10}$ Sobre la fallida negociación para obtener los cien hábitos de Santiago para la gobernación de Santa Marta, ver Fernández de Oviedo, 1991, vol. 3: 62.

${ }^{11}$ Fernández de Oviedo, 2010/1526: 128. 
esgrimían sus colegas para racionalizar la conquista no era nada menos que una «destrucción»-el mismo término que la gran némesis de Oviedo, Bartolomé de las Casas (1484-1566), inmortalizaría años más adelante con su Brevissima relaçion de 1552: «los que han seido causa de este daño llaman pacificado a lo despoblado; y yo [es decir, Oviedo] por más que pacífico lo llamo destruido».

No hay que olvidar la particular sagacidad cortesana de Oviedo: a diferencia de Las Casas, cuyo humanitarismo gradualmente lo radicalizara a favor de los derechos de los Indios y en contra de los títulos de conquista a las Indias, Oviedo sabía perfectamente sopesar la ventaja que sus arengas contra el maltrato de los Indios en Tierra Firme le lograrían sobre enemigos como Pedrarias en la fiera competencia por percibir mercedes por servicios prestados a la Corona en ultramar. Es más, la aurora de la historiografía natural de las Indias como género autóctono en el Sumario forma parte del esfuerzo de Oviedo por ganarles la partida a Pedrarias y sus compinches: entre 1523 y 1525 , cuando Oviedo se encontraba ante la corte rogando para deponer a Pedrarias como gobernador de Panamá, Carlos V y su consejo recibieron no sólo un reporte sobre los abusos cometidos en Tierra Firme, sino también un segundo reporte sobre las tierras y gentes de las Indias ${ }^{12}$. No hay duda de que en el proceso de denunciar la corrupción de sus colegas en Tierra Firme ante la corona, el oficial que había sido encargado de supervisar las fundiciones de oro en la expedición de Pedrarias a Tierra Firme llegó a concebir la labor de enumerar y describir la cultura, la fauna, la flora, y los minerales de las Indias como extensión lógica de su cargo como veedor del tesoro aurífero de Tierra Firme. Así pues la figura del capaz y exigente naturalista que se ensaya en el Sumario recibe su hálito vital del funcionario que se viera a sí mismo como tesorero y guardián del amplísimo botín natural y humano del emperador Carlos V en las Indias ${ }^{13}$.

En el proemio al Sumario, Oviedo adoptaba a Plinio como modelo, insistiendo en que la monumental Historia natural cuidadosamente intercalaba lo que el autor romano había oído de segunda mano con lo que había leído y con lo que había presenciado "como testigo de vista» ${ }^{14}$. Oviedo por otra parte le advertía al emperador que había dejado en su residencia de Santo Domingo los

\footnotetext{
12 El primer reporte, hoy en el Archivo General de Simancas (Patronato Real, Arca de Indias, legajo 7), se puede consultar en Saco, XIII (1883).

${ }_{13}$ Oviedo era asimismo consciente de que la presentación de la «cornucopia» americana a Carlos V coincidía con el auge y optimismo que marcaron los primeros años de su imperio (Carrillo Castillo, 2004: 73).

${ }^{14}$ Fernández de Oviedo, 2010/1526: 65.
} 
copiosos originales de una crónica de España que llevaba escribiendo «desde que tuve edad para ocuparme en semejante materia», así como los originales de «todo lo que he podido comprehender y notar de las cosas de la Indias», por lo cual el autor no contaba en la corte con nada más que «lo que en la memoria está y puedo della aquí recojer» ${ }^{15}$. Así le rogaba a Carlos V que lo disculpase «si no fuere tan ordenado lo que aquí será contenido, ni por tanta regla dicho», y le ofrecía el Sumario como mero avance improvisado del extenso tratado que ya se encontraba escribiendo y cuya primera parte habría de entregar años más tarde a la imprenta en Sevilla bajo el título de Historia general y natural de las Indias $(1535)^{16}$. En aquella voluminosa obra, como bien se sabe, Oviedo habría de añadir a sus considerables destrezas como testigo de vista y como lector, informes de primera mano recogidos de distintas partes de las colonias.

Pero el Sumario es mucho más sistemático de lo que Oviedo se aventura a admitir, aún cuando quepa también caracterizarlo como una especie de «guía de viajes» práctica o como «una miscelánea... de extrañezas sobre las plantas, animales, gentes y culturas de las Indias» ${ }^{17}$. Ya en este breve tratado ensayaba el amplio espectro de perspectivas que hallarían mayor detalle en la General y natural historia. En calidad de naturalista y etnógrafo, Oviedo constantemente se maravilla ante una naturaleza que, como detallaremos más adelante, parece tan perfecta, prolífica y hospitalaria como podría haberse hallado en el paraíso terrenal. Se admira asimismo del gran ingenio de sus gentes para explotar, rebasar o incluso mejorar los recursos de aquella naturaleza. Recordemos sólo el cuidado que Oviedo pone al describir la técnica de los indios en la fabricación de objetos cotidianos como las «camas en el aire» que hoy conocemos como hamacas; las canoas vaciadas a partir de troncos hercúleos y capaces de transportar «ciento, y ciento treinta hombres» por los mares del caribe; o las contrapciones hechas de distintas maderas que se frotaban entre sí para generar fuego ${ }^{18}$. O recordemos la admirativa especificidad con que

15 Ibidem: 66.

16 El Sumario era así también una especie de avance publicitario para la Historia general (Baraibar, 2010: 15).

17 Ver, respectivamente, Baraibar, 2010: 25-26 y Merrim, IV (Minneapolis, MN, 1989): 170, traducción mía. Sobre el carácter sistemático del Sumario, ver los recientes análisis de Prieto, CXXIV/2 (Baltimore, MD, 2009). Paden, XVI/2 (New York, NY, 2007). Sánchez Jiménez, XIII/2 (New York, NY, 2004). Sobre la estructura de la obra, ver Baraibar, 2010: 17-19 y Carrillo Castillo, 2004: 99 y páginas siguientes.

18 Sobre las hamacas de los indios de Tierra Firme, ver el capítulo 10 de Fernández de Oviedo, 2010/1526: 140-141. Sobre la construcción de sus canoas y el arte de generar fuego, ver el capítulo 78 de Fernández de Oviedo 2010/1526: 304 y 306-307. 
Oviedo narra la caza de «ánsares bravas» en las lagunas de Cuba: los indios echaban a flotar «grandes calabazas vacías y redondas» para acostumbrar a los gansos a posarse en ellas; luego las horadaban y se las colocaban «en la cabeza hasta los hombros» para nadar camuflados entre los gansos; y cuando algún ave desprevenida se posaba en su totuma, los indios la apartaban imperceptiblemente de los demás gansos, para luego «saca[r] la mano, [asirla] por las piernas, met[erla] debajo del agua, y ahog[arla]» ${ }^{19}$.

No obstante su meticulosa apreciación del ingenio indígena, en calidad de partícipe de la conquista y colonización, e incluso al tiempo que denuncia los abusos de sus colegas contra los indios, Oviedo también imagina el Nuevo Mundo como un espacio cuasi-infernal, un espacio secuestrado por el mal, un mal quizás encarnado y patente en los huracanes que ocasionalmente devastan la tierra:

cuando el demonio los quiere espantar [a los indios], promételes el huracán, que quiere decir tempestad; la cual hace tan grande, que derriba casas y arranca muchos y muy grandes árboles; y yo he visto en montes muy espesos y de grandísimos árboles, en espacio de media legua, y de un cuarto de legua continuado, estar todo el monte trastornado, y derribados todos los árboles, y raíces de muchos de ellos para arriba, y tan espantosa cosa de ver, que sin duda parecía cosa del Diablo, y no de poderse mirar sin mucho espanto ${ }^{20}$.

Los habitantes de aquella tierra, particularmente los de la tierra firme Centro y Suramericana no son para Oviedo nada menos que acólitos del demonio («engañados por él») cuya débil naturaleza los compele a fraguar los más exquisitos crímenes contra Dios, la humanidad y la naturaleza, desde la idolatría, hasta el suicidio en masa, el sacrificio humano o el canibalismo, por no hablar de la promiscuidad, el aborto, la sodomía y el bestialismo ${ }^{21}$.

Tan extremos y opuestos retratos de las Indias y de sus gentes -entre el edén y el infierno, entre el idilio más sublime y la monstruosidad más abyecta- pueden parecernos irreconciliables. Pero, como espero demostrar, estas aparentes contradicciones en el pensamiento de Oviedo, se explican al relacionarlas con un paradigma cosmológico que hoy conocemos como la teoría de las cinco zonas y que concierne la distribución de vida alrededor del globo (fig. 2). Esta teoría, a veces atribuida a Parménides (s. V antes de Cristo), dividía la región de los elementos con relación al avance y retroceso

19 Fernández de Oviedo, 2010/1526: 104-105.

20 Ibidem: 131-132.

${ }^{21}$ Para el inventario de agravios que esgrime Oviedo contra los Indios, consúltense especialmente los capítulos 9 y 10 del Sumario, en los cuales se trata de la tierra firme, Fernández de Oviedo, 2010/1526, 107-145. 


\section{FigURA 2}

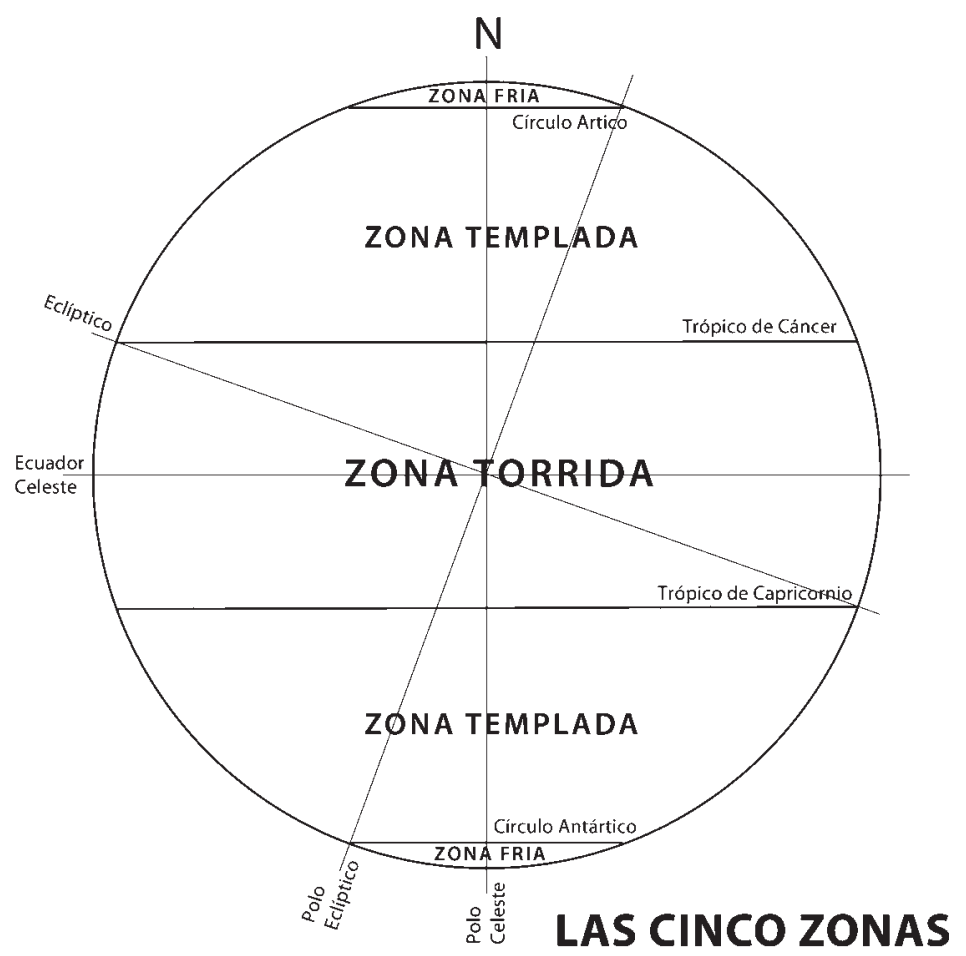

Ilustración de la teoría de las cinco zonas, atribuida hoy a Parménides (s. V antes de Cristo). Preparada por el autor.

del sol a lo largo del círculo inclinado del eclíptico. Los trópicos de Cáncer y Capricornio marcaban la declinación máxima del sol hacia el norte y hacia el sur del círculo ecuatorial. Los polos ártico y antártico marcaban la correspondiente declinación del polo del eclíptico o del zodíaco.

Las dos zonas más allá de los círculos ártico y antártico se suponían inhóspitas dada la relativa ausencia de calor del sol. La zona «caliente» entre Cáncer y Capricornio se suponía también inhóspita dado el relativo exceso de calor solar. En virtud de esta división latitudinal del globo, el mundo habitable conocido antes de la llamada era de la exploración habría formado un angosto corredor templado y, por ende, civilizado del sistema geográfico configurado por África, Asia y Europa. Este corredor civilizado se habría visto sitiado hacia el norte y hacia el sur por los extremos de frío y calor en el ártico y trópico 
incivilizados. Etiopía e India, es decir, el África subsahariana y la cuenca extendida del Océano Indico caían en los márgenes quemados y hostiles del mundo habitado conocido. Así se puede apreciar en el icónico mapamundi que tiende a acompañar las ediciones impresas del Comentario al sueño de Escipión de Macrobio (s. V después de Cristo), que, irónicamente, ilustra la supuesta no habitabilidad de la zona tórrida a la vez que teoriza una masa continental autóctona en la «[zona] templada de los antípodas desconocida para nosotros» (fig. 3).

La India, claro está, no era el país que hoy conocemos por tal. Como bien lo ilustra el famoso globo que preparase Martín Behaim para la ciudad de Nuremberg (1492), la cartografía más sofisticada inmediatamente anterior a los descubrimientos colombinos pintaba la India como un complejo sistema geográfico organizado en torno a aquel accidente distintivamente «tropical» que hoy conocemos como Océano Indico (fig. 4). La India se extendía desde las islas de Madagascar y Zanzíbar en el extremo suroriental del continente africano, a todo lo largo de la costa oriental del África y de la meridional del Asia, hasta llegar a un Japón supuestamente tropical y a un archipiélago circundante que se explayaba indefinidamente hacia el oriente en dirección al África subsahariana.

Se solía suponer que dentro de tales trópicos, sólo accidentes geográficos como el Río Nilo y el Río Ganges podían forzar a una naturaleza circunstancialmente rica en calor y humedad -los ingredientes primarios para la generación de la vida - a generar las maravillas y monstruos vegetales, animales, y humanos que desde siempre habían cautivado a los geógrafos mediterráneos. A nosotros los tropicales, ciertamente se nos consideraba humanos. Pero éramos humanos por fuera de los parámetros ordinarios de la naturaleza, muestras de los caprichos de la madre naturaleza o de la omnipotencia de Dios. Como nos lo recuerda el mismo Plinio al que sigue Oviedo, la Etiopía y la India eran lugares donde la naturaleza había ingeniado a las naciones monstruosas «como entretenimiento para sí misma, y como fuente de admiración para nosotros» ${ }^{22}$. O recordemos las palabras del comentarista de Aristóteles más prolífico entre los árabes, Averröes (Ibn Rushd), quien afirma que los cuerpos y las costumbres tropicales «no son naturales» o se hallan «por fuera de la naturaleza» ${ }^{23}$. En efecto, según la teoría de las cinco zonas, la naturaleza tropical era madre por excepción y sus criaturas no podían ser más que invertidos biológicos y morales que siempre se hallaban royendo los bordes del mundo civilizado.

\footnotetext{
22 Plinio, 1938-1963, vol. 2: 526-527.

${ }^{23}$ Averröes, [1562] 1962: 438v y 440v.
} 


\section{Figura 3}

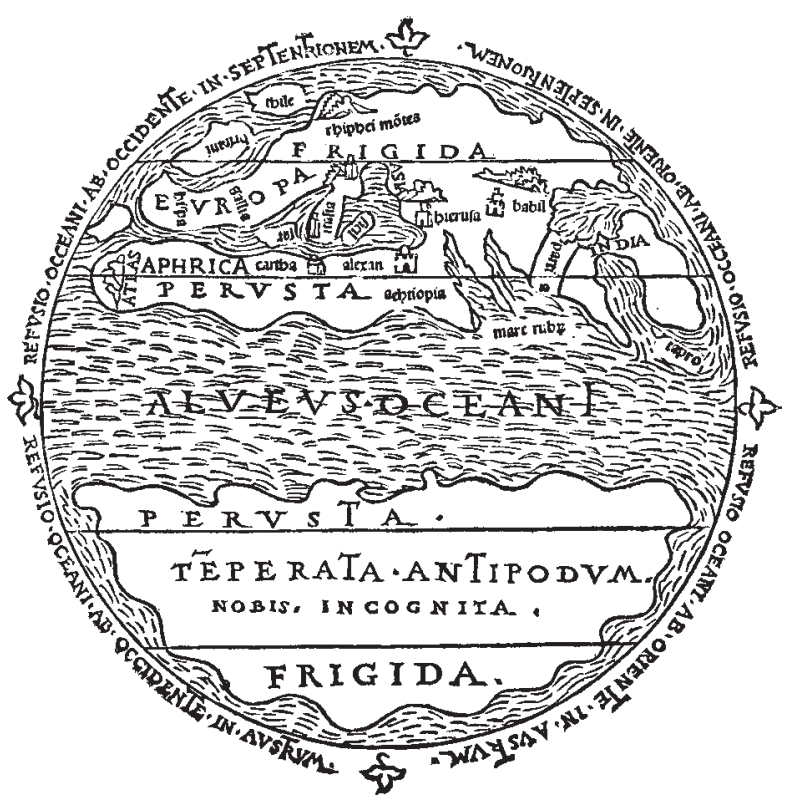

El mappamundi macrobino. Reproducción de Ambrosio Aurelio Teodosio Macrobio, In somnium Scipionis expositio: Saturnalia, Brescia, 1483, viii v. Cortesía de la Biblioteca John Hay, Universidad de Brown, Providence, Rhode Island, Estados Unidos.

Figura 4

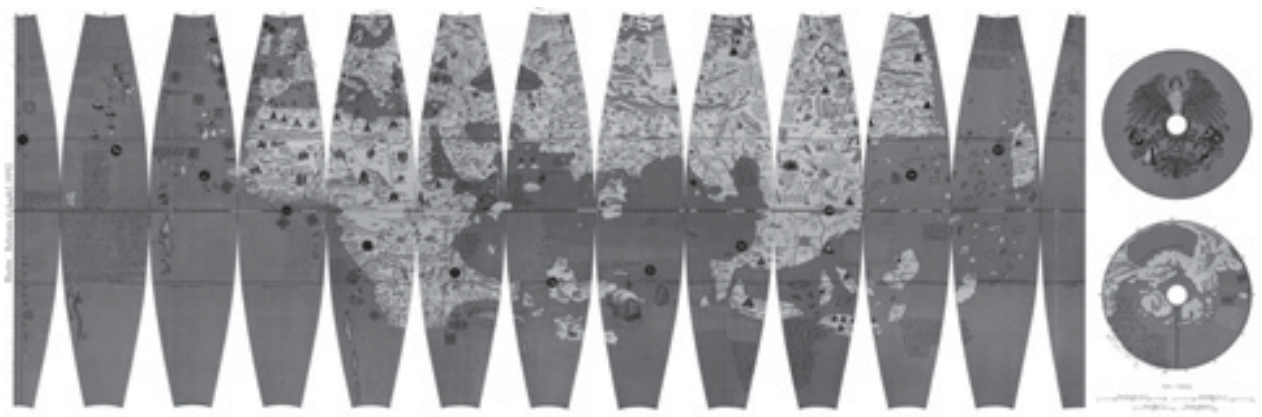

El globo de Martín Behaim, 1492. Reproducido a partir de E. G. Ravenstein, FRGS, Martin Behaim: His Life and His Globe, Londres, George, Philip and Sons, 190. El globo original se encuentra en el Germanisches Nationalmuseum, Nuremberg, Alemania. 
El gradual despertar de la Europa moderna a los recursos naturales y humanos de los trópicos, sin duda fue minando la autoridad de este paradigma cosmológico. Pero tal paradigma de ninguna manera perdió su atractivo para los naturalistas que en los siglos XVI y XVII se ocuparon de describir América. Al contrario, yo afirmaría que es precisamente la inicial conceptualización de las colonias españolas en América como dominio tropical $-\mathrm{y}$, por ende, generalmente cálido- distinto de una Europa templada, lo que le permite a Oviedo articular una paradoja como la que en el Sumario se refiere a las Indias y sus habitantes. Al fin y al cabo, estamos hablando de un universo científico en el que la gran diversidad observada en el mundo físico desde la antigüedad se juzgaba reducible a las cuatro propiedades fundamentales que subyacían de los elementos y sus compuestos: el calor y el frío, y la sequedad y la humedad ${ }^{24}$. Según este esquema, no se esperaría hallar diferencias más fundamentales en el mundo natural que aquéllas entre las latitudes medias o «templadas» de la Europa mediterránea y las latitudes extremas «frías» o «calientes» de las regiones polares y de los trópicos. Así, en verdad, es la «tropicalidad» de las Indias lo que le permite a Oviedo empezar a articular diferencias y semejanzas sistemáticas entre las naturalezas y culturas del Viejo y Nuevo Mundo. Por otra parte, la «tropicalidad» americana también es, en parte, lo que le permite a Oviedo interpretar testimonio de vista sobre las Indias Occidentales a la luz de textos tradicionales como la Historia natural de Plinio, obra que trataba sobre lugares tropicales como Etiopía e India. Es más, en la medida en que la temprana modernidad imagina la naturaleza como raíz de lo cultural, la «tropicalidad» americana le permite a Oviedo contribuir a un debate legalista que se remonta tal vez al año de 1495, cuando Colón despachara los primeros esclavos recogidos de las Antillas para el mercado de Sevilla ${ }^{25}$. Oviedo entiende perfectamente que desde los primeros años del siglo dieciséis los defensores de la conquista habían intentado evadir el debate sobre la legalidad de las bulas en virtud de las cuales el papa Alejandro VI supuestamente «donaba» las Indias a Aragón y Castilla. Y lo habían intentado evadir postulando precisamente que era la naturaleza misma del Nuevo Mundo lo que justificaba la colonización de las Indias y el avasallamiento o esclavización de sus habitantes. Oviedo se encuentra agudamente consciente de que los territorios explorados por Colón, a quien

${ }^{24}$ Lloyd, LXXXIV (Cambridge, UK, 1964).

${ }^{25}$ Los contornos de este debate los conocemos gracias en parte a Hanke, 1959 y a Pagden, 1982. Adorno, 2008, esgrime significativas objeciones al papel que estos historiadores le han asignado a los conceptos de naturaleza y esclavitud dentro de este debate. 
FiguRA 5

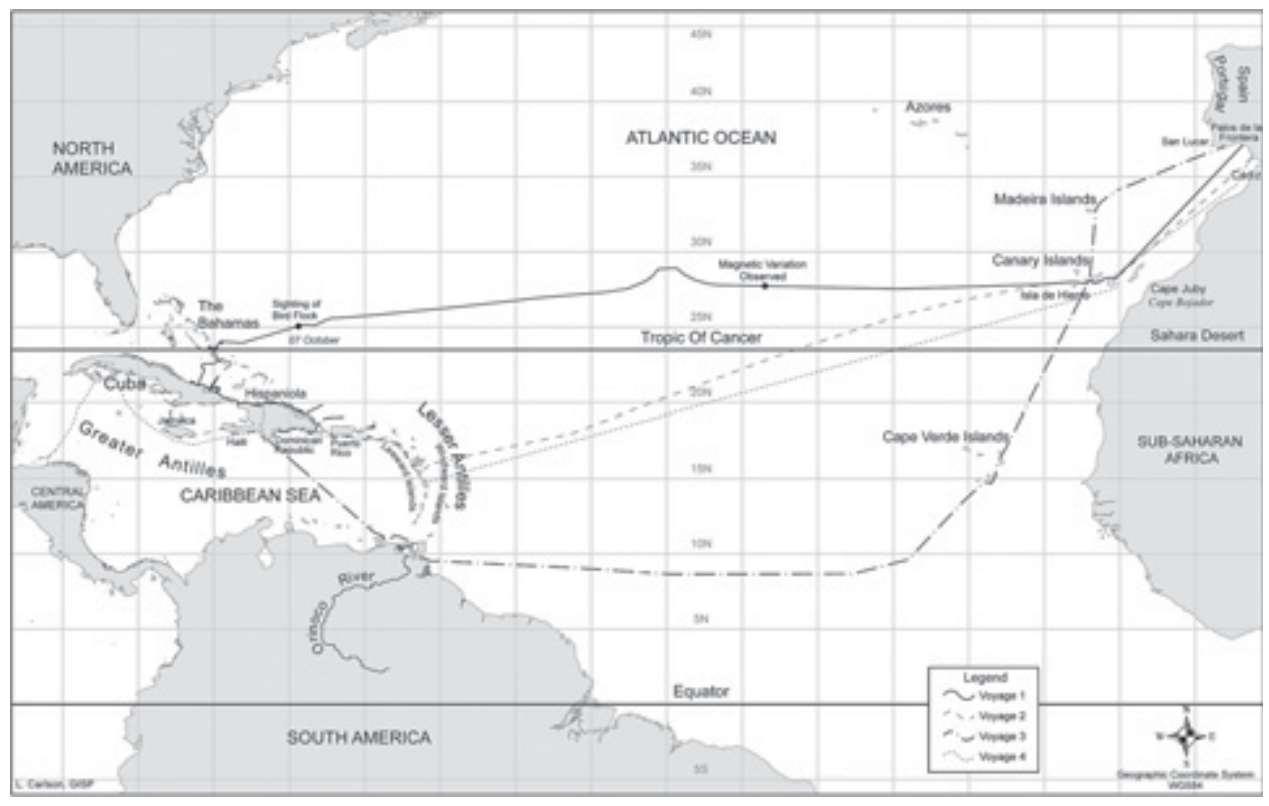

Las cuatro rutas colombinas, 1492-1504. Mapa basado en las rutas de Samuel Eliot Morison, Admiral of the Ocean Sea: A Life of Christopher Columbus, 2 vols., Boston, Little Brown, 1942. Preparado por Lynn Carlson, Ciencias Geológicas, Universidad de Brown, Providence, Rhode Island, Estados Unidos.

Oviedo idealizaba como el Hércules de los modernos, no se hallaban meramente al occidente del mundo habitado conocido por geógrafos antiguos como Tolomeo. Los territorios que Colón había terminado por llamar Indias Occidentales, tal vez sospechando que no había navegado lo suficiente hacia el oeste para alcanzar la India, también se hallaban hacia el sur de la Europa mediterránea, cerca y dentro de la llamada zona tórrida (fig. 5).

Pues bien, éste todavía era el caso treinta años más tarde, cuando Oviedo escribía el Sumario, de las colonias que España había establecido en el complejo circumcaribeño -ya fuera el caso de las colonias en las Antillas Mayores, como el de las colonias en Tierra Firme, desde el valle de México hasta la provincia de Cumaná en lo que es hoy la Venezuela nororiental-. Así pues, la llamada «carrera de Indias», según el Sumario de Oviedo, implicaba primeramente un descenso desde San Lúcar de Barrameda en Sevilla (que se sabía por encima de los 36 grados de latitud norte entonces asignados al paralelo que pasaba 
por el estrecho de Gibraltar) hasta las Islas Canarias ${ }^{26}$. Desde las Canarias se descendía aún más a través del Atlántico hasta las islas de barlovento en las Antillas Menores, a saber, «Todos Sanctos, Marigalante, la Deseada, Matitino, la Dominica, Guadalupe, Sant Cristóbal, etc. ${ }^{27}$. La versión detallada de esta ruta que habría de ofrecer Oviedo en la Historia general y natural de las Indias precisaría un descenso de las Canarias a las Antillas Menores que iba desde los 27 grados y medio de la Isla de Hierro hasta los 14 grados de la isla De$\operatorname{seada}^{28}$. Desde las Antillas Menores, las velas ascendían otra vez siguiendo el rosario antillano hasta la ciudad de Santo Domingo en la costa meridional de La Española, que el Sumario ya explícitamente situaba a 19 grados de latitud norte ${ }^{29}$. Desde Santo Domingo, las velas entonces se dispersaban por el Caribe en todas las direcciones hacia Tierra Firme, cuyo punto más meridional el $\mathrm{Su}$ mario asimismo precisaba en el Golfo de Urabá a una latitud de 6 grados y 30 minutos norte ${ }^{30}$. Según Oviedo, el Darién se hallaba tan cerca del Ecuador que «todo el tiempo del mundo son los días y las noches casi del todo iguales»; tan cerca del Ecuador que «está allí [la estrella] del norte muy abajo, y cuando las guardas están en el pie, no se pueden ver, porque están debajo del horizonte» ${ }^{31}$.

Como se puede esperar, tal precisión técnica por parte de Oviedo sólo habría de adquirir mayor especificidad en la historia oficial que ya anunciaba Oviedo en su Sumario, es decir, en la Historia general. Pero de momento esta información le era suficiente para ofrecerle a sus lectores una observación fundamental sobre la naturaleza de la Tierra Firme: «la tierra es naturalmente calurosa y por la providencia de Dios templada $\rangle^{32}$. Invocando la teoría de las cinco zonas, Oviedo continua: «no sin causa los antiguos tuvieron que la tórrida zona, por donde pasa la línea equinocial, era inhabitable, por tener el sol más dominio allí que en otra parte de la espera y estar justamente entre amos trópicos de Cáncer y Capricornio» ${ }^{33}$. Pero, según Oviedo, Dios habría operado una especie de excepción en la naturaleza tropical. La deidad habría contrarrestado el calor y la sequedad universales de la región imponiendo el frío y la humedad de incontables accidentes geográficos, a saber, lluvias mil, caudalosos ríos, quebradas, fuentes y lagos. Estos accidentes no sólo habrían atenuado los efectos letales del calor solar, sino que habrían causado la monstruosa proliferación de las raíces de

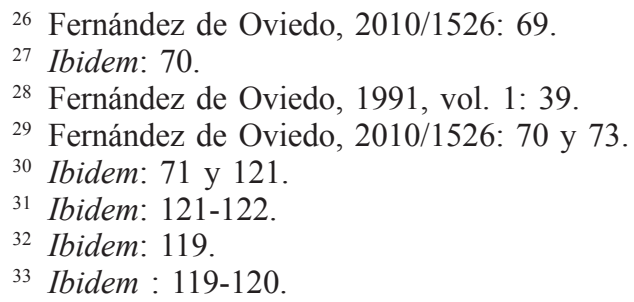


Figura 6

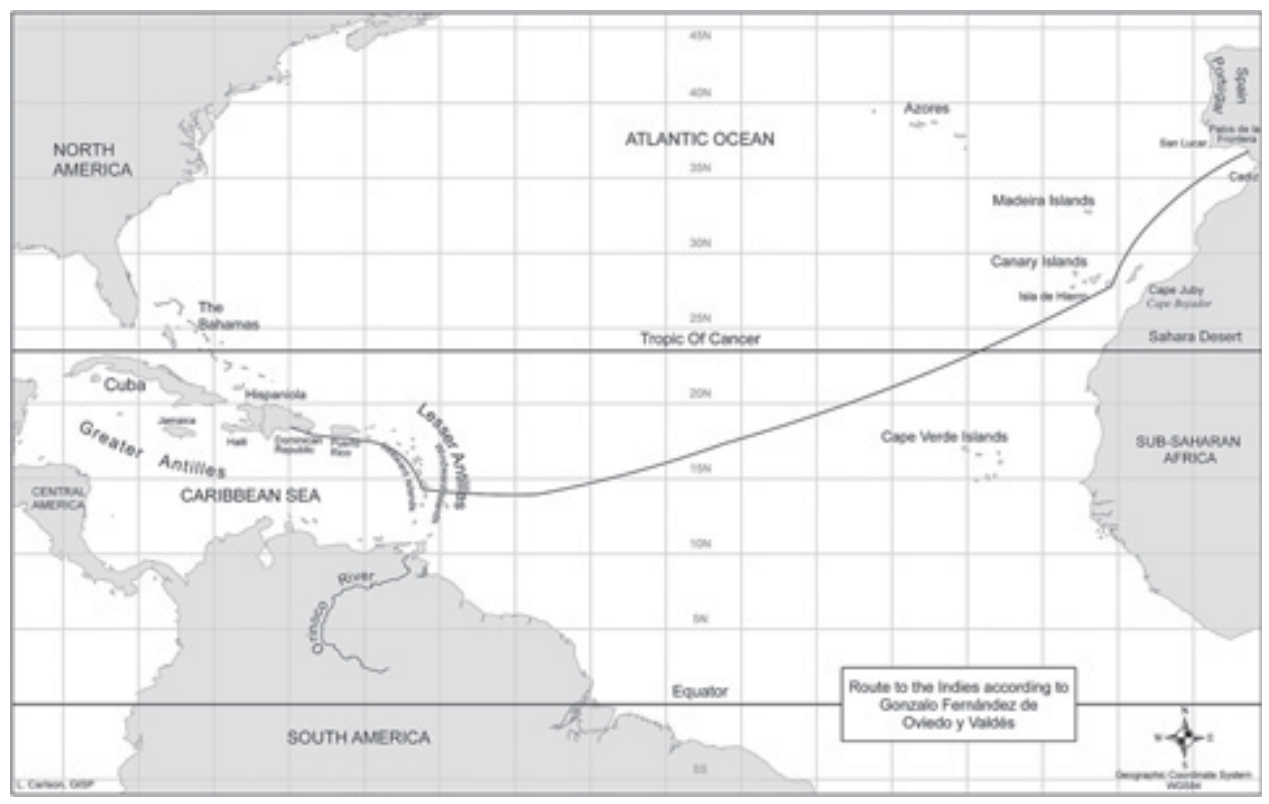

La llamada carrera de Indias, según Gonzalo Fernández de Oviedo. Mapa basado en la información que provee el autor en la edición príncipe del Sumario: Oviedo, dela natural hystoria delas Indias, Toledo, Ramón Petras, 1526: xix recto. Preparado por Lynn Carlson, Ciencias Geológicas, Universidad de Brown, Providence, Rhode Island, Estados Unidos.

árboles y plantas mucho más allá del volumen del follaje tropical. Valga decir que la abundante combinación de la humedad suplida por las aguas con el calor de los rayos solares habría creado condiciones ideales para la generación de la sublime biodiversidad con la que Oviedo y sus coetáneos europeos se habían topado (no sin sorpresa, admiración o terror), en las Indias Occidentales.

Es en el inventario de los recursos naturales de La Española, isla en la cual Oviedo eventualmente se radicaría como custodio del fuerte de Santo Domingo, donde nos encontramos con el más rico cuadro del botín edénico que ofrecía una India templada por la providencial mano de Dios: «si un príncipe no toviese más señorío de aquesta isla sola», afirma Oviedo, «en breve tiempo sería tal que ni le haría ventaja Secilia ni Inglaterra ${ }^{34}$. El botín de La Española incluía las «más ricas minas y de mejor oro que hasta hoy en parte

${ }^{34}$ Ibidem: 76. 
del mundo en tanta cantidad se ha hallado ni decubierto». La prodigalidad de la naturaleza no se limitaba a las «muchas frutas naturales de la misma tierra», o a los incontables peces y aves, o a las iguanas terrestres que regían la isla, o a las ratoniles hutías y curíes que conformaban la dieta de los indios ${ }^{35}$; esta prodigalidad incluso se extendía a una población humana que Oviedo más tarde, en la General y natural historia, contaría por encima de un millón antes de que todos los males de la conquista la diezmasen: la guerra, el hambre, las plagas, el trabajo forzado y el suicidio en masa ${ }^{36}$. Pero aún más importante para establecer y sostener una colonia ultramarina próspera era el hecho de que la naturaleza de la Española hubiese perfeccionado, incrementado y multiplicado todo tipo de productos agrícolas, no sólo aquéllos que naturalmente prosperaban en tierras tropicales o subtropicales, como el algodón, la caña de azúcar o la purgativa cañafístola; sino también productos hortícolas que desde hacía mucho tiempo se los había cultivado en, o aclimatado a, las latitudes templadas de la península ibérica ${ }^{37}$. Por último, el suelo de la Española también generaba «los mejores pastos del mundo» para el ganado importado de Iberia. Tanto así que los ganados vacunos habían crecido hasta llegar a las mil, dos mil, cuatro mil y ocho mil cabezas, y que todas las ovejas, los cerdos y las vacas que los colonos no habían podido sostener se habían vuelto salvajes y vagaban dispersos por toda la isla e incluso amenazaban con abrumar a la población humana ${ }^{38}$.

Claro está, no todo iba de viento en popa en aquel paraíso. Como todo padre o madre sobreindulgentes, la naturaleza tropical también había causado la proliferación de una generación entera de colonos indolentes, perezosos y no perseverantes a los cuales poco les interesaba trabajar la tierra. Así, aunque «todas las cosas que se siembran y cultivan de las que hay en España, se hacen muy mejor y en más cantidad que en parte de nuestra Europa», muchas se dejan de cultivar o se pierden porque los colonos, explica Oviedo, «quieren el tiempo que las han de esperar para le ocupar en otras ganancias y cosas que más presto hinchan la medida de los codiciosos», a saber, el comercio, la excavación del oro y la pescadería de perlas ${ }^{39}$. Los vicios que repudiaba Oviedo en los colonos no provenían únicamente de que lo hubieran tenido todo en la naturaleza de la isla y por lo tanto no apreciaran en nada su riqueza. Era la naturaleza misma la que supuestamente imprimía estos vicios en

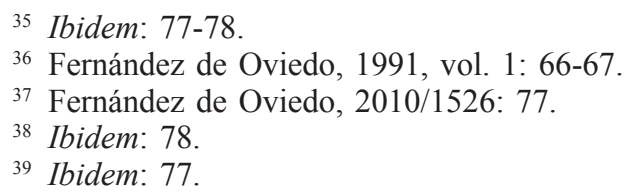


los cuerpos humanos transplantados de las latitudes templadas de una Europa civilizada a las latitudes tórridas de las Indias. La preocupación de Oviedo por los efectos de la naturaleza de las Indias en las poblaciones humanas se hace particularmente evidente en el tratamiento que ofrece el Sumario sobre los tigres, la yuca, los murciélagos y los seres humanos.

Consideremos brevemente la teoría de diversificación natural que invoca Oviedo en su referencia a «las diversidades de las provincias y constelaciones donde se crían [las criaturas]». Esta teoría de diversificación postulaba que la naturaleza de todo cuerpo elemental era, primordialmente, función de las causas universales, es decir, de las propiedades que comunicaban los cuerpos celestes a ese cuerpo elemental en forma de radiación: la radiación celeste comunicaba la forma y, por ende, el movimiento propio de los cuatro elementos y sus compuestos $^{40}$. La naturaleza de cada cuerpo elemental era, secundariamente, función de aquellas causas que operasen a favor o en contra de las causas universales, es decir, de las propiedades que los elementos circundantes inmediatamente comunicaban a dicho cuerpo elemental. Pero era principalmente la radiación celeste lo que le comunicaba a dicho cuerpo su particular «naturaleza». A cada instante en el tiempo, cada punto en la región de los elementos y, por ende, cada lugar, constituía el centro de un horizonte único con su propia configuración de estrellas y planetas. El complejo de rayos proveniente de esta configuración celestial única convergía sobre dicho punto, comunicándole propiedades que éste no compartía con ningún otro punto, por más cerca que estuviese de aquel otro. En otras palabras, se pensaba que cada lugar a cada momento en el tiempo generaba una cosa que era totalmente única a aquel lugar y que sin embargo sufría alteraciones o incluso mutaba para convertirse en algo enteramente distinto. Obviamente, lugares similares daban pie a naturalezas similares, y lugares distintos -especialmente lugares separados por latitud-daban pie a naturalezas distintas. Pero cada lugar bajo los cielos -cada hábitat- supuestamente comunicaba a cada cuerpo una naturaleza enteramente única.

Así pues, volvamos a los ejemplos que utiliza Oviedo: la yuca bien puede ser yuca en la Española o en Tierra Firme; los murciélagos, murciélagos en España o en las Indias; los tigres, tigres en la legendaria India o en las nuevas Indias; y los hombres, hombres en un reino o en otro. Pero cada criatura presentaba propiedades físicas únicas $\mathrm{y}$, por ende, se hallaba predispuesta a comportarse de maneras únicas que correspondían a las causas universales y accidentales igualmente únicas que actuaban de diversas maneras en la com-

40 Para una discusión de este sistema explicativo, consultar el capítulo 4 de Wey Gómez, 2008: 229-291, donde se pueden seguir los planteamientos fundacionales del naturalista más destacado e influyente del aristotelismo en el occidente latino, Alberto Magno (ca. 1200-1280). 
plexión de dicha criatura en cada momento. En los términos utilizados por Oviedo, la naturaleza irrepetible de cada criatura en la región de los elementos obedecía a las «constelaciones» y a las «provincias». Así pues, se podía esperar que el jaguar y el tigre de Bengala poseyesen naturalezas similares, pues ambos eran nativos de las mismas latitudes tropicales generales. Y también se podía esperar que ambos grandes felinos tuviesen naturalezas más parecidas entre sí que con respecto a los felinos mucho más pequeños que se encontraban en las latitudes más altas y templadas de Europa. Pero, según Oviedo, no se podía dar el mismo nombre al jaguar con sus manchas redondas que al tigre de la India, por la sencilla razón de que las Indias Occidentales no conformaban la misma provincia que la India de Plinio. Y así, la relativa lentitud del jaguar con respecto al tigre de Bengala requería añadir el jaguar como nueva especie al género de los grandes gatos conocidos en la antigüedad.

Ahora bien, la diferencia de lugar que jugaba un papel aun más evidente que cualquier otra diferencia en la diversificación natural era la diferencia de latitud. Sencillamente no existían felinos grandes en la Europa mediterránea del tamaño de los felinos que se podía encontrar en Etiopía e India. La yuca sembrada a los 19 grados de latitud norte de La Española parecía buenísima para lidiar guerra biológica contra el enemigo, mientras que aquélla sembrada en las latitudes ecuatoriales de Tierra Firme parecía buenísima para la digestión. Y los murciélagos que surcaban las latitudes templadas de España carecían de la mortal mordida de sus infames congéneres en las latitudes ecuatoriales de Tierra Firme. Más al punto de nuestra discusión, como lo dice Oviedo, «animosos son los hombres y de mucho atrevimiento en algunos reinos, y tímidos y cobardes naturalmente en otros» ${ }^{41}$.

Como es de esperar, para Oviedo y sus contemporáneos europeos no existían diferencias entre los lugares y las gentes más universales y absolutas que las diferencias latitudinales que postulaba la teoría de las cinco zonas entre las bandas fría, caliente y templada del globo (fig. 2). La referencia aparentemente inocua que hace Oviedo a la animosidad o atrevimiento y a la timidez o cobardía de los hombres en distintos reinos obedece a un modelo geopolítico de larga duración en Occidente. Este modelo conectaba, por una parte, la centralidad o medianía geográfica con el balance o salud física y con la virtud moral; y por otra parte, la marginalidad o extremismo geográfico con el desequilibrio o la enfermedad física y con el vicio moral. Este modelo geopolítico bien puede encontrar su formulación más temprana en el tratado hipocrático que conocemos como Aires, aguas y lugares $^{42}$. Pero en el ámbito de la amarga polémica legalista que suscitó la ocupación española de las Américas, este modelo nos traslada inmediatamente

${ }^{41}$ Fernández de Oviedo, 2010/1526: 148.

${ }^{42}$ He consultado la versión en griego e inglés. Hipócrates, 1984. 
a la tradición de los comentarios de Aristóteles en su obra sobre la política ${ }^{43}$. Oviedo ciertamente tuvo que haber conocido la versión de este modelo geopolítico en la Historia natural de Plinio, quien afirmaba que la zona fría (es decir el ártico) generaba gente de piel blanca, fiera pero imprudente y, por lo tanto, incapaz de gobernarse a sí misma. La zona tórrida (el trópico) generaba gente de piel oscura, sabia (sapientes) pero tímida, y por lo tanto también incapaz de gobernarse a sí misma. Mientras que la zona templada (es decir, la Europa mediterránea) generaba gentes de mediana complexión con «moderadas costumbres, agudos sentidos y fértiles intelectos» que la habilitaban para ejercer la autoridad política que eludían sus vecinos del ártico y del trópico ${ }^{44}$. Pero la terminología que despliega Oviedo - «animosidad» y «atrevimiento» versus «timidez» y «cobardía»- le liga más directamente a aquellos lectores de Aristóteles que, a la luz del Descubrimiento, habían utilizado la caracterización que ofrece Aristóteles de los asiáticos como «inteligentes e ingeniosos» pero «carentes de espíritu», para difamar a los habitantes de las Indias como esclavos por naturaleza ${ }^{45}$.

Esta geografía tripartita es menos simplista de lo que aparenta. En realidad sintetiza todo un complejo sistema explicativo cuyas raíces surgen de la preocupación de Occidente por la problemática dinámica entre el alma racional y el cuerpo físico. Para cuando este modelo cayera en manos de Oviedo, ya se hallaba minuciosamente inscrito dentro de un sistema filosófico y técnico que explícitamente ligaba el concepto de lugar que ofrecían Aristóteles y sus comentaristas en el ámbito de la física con el concepto de virtud en el ámbito de la ética y la política aristotélicas. Este sistema de conocimiento daba articulación lógica a disciplinas que ya no existen, al menos no en el sentido que les dio la temprana modernidad, o cuyos vínculos entre sí no tienen sentido obvio para nosotros: entre estas disciplinas se pueden contar la teología, la física, las matemáticas, la geometría, la astronomía, la astrología, la óptica, la psicología y la fisiología de los seres humanos, las bestias y las plantas, así como aquellas ramas de la filosofía moral que conocemos hoy como ética, economía y política.

Ya hemos mencionado que en la cosmología heredada de los griegos y de los árabes, los cuerpos celestes comunicaban la forma y, por ende, el movimiento a los cuerpos elementales y sus compuestos. En el dominio de la psicología y la fisiología humanas, esto significaba que los cuerpos celestes podían afectar no sólo los humores del cuerpo, sino también el comportamiento humano. En la medida en que cada individuo o colectividad cedía a la naturaleza que le

\footnotetext{
${ }^{43}$ Aristóteles, 1985, vol. 2: 2107.

${ }_{44}$ Plinio, 1938-1963, vol. 1: 320-323.

45 Ver el capítulo 1 de Wey Gómez, 2008: 59-106, especialmente las pp. 100-106.
} 
comunicaban los cielos, su comportamiento estaba en función de su «lugar» en el cosmos. Lo que habría de preocupar a los que propusieron la «esclavitud natural» en la España imperial para justificar el avasallamiento o la esclavitud de los indios era precisamente la aptitud o ineptitud del alma humana para dominar la naturaleza que los lugares fríos, calientes, o templados, inducían en el cuerpo.

Obviamente no podemos detenernos para describir este sistema explicativo. Baste con mencionar que el humor que en el cuerpo se asociaba con distintos grados de inteligencia y animosidad (o valentía) en los humanos era la sangre ${ }^{46}$. El frío en el ártico supuestamente cerraba los poros de la piel, atrapando el calor vital en la sangre-calor que explicaba la audacia de los nórdicos. La misma clausura de los poros prevenía la purificación de la sangre, lo que en cierto sentido contaminaba el llamado spiritus o pneuma. El spiritus era la sustancia más noble y rara en la sangre, encargada de mediar entre el alma y el cuerpo; era, de alguna manera, el medio a través del cual el alma exhalaba vida en el cuerpo y el medio a través del cual el cuerpo comunicaba las «formas» o «imágenes» del mundo sensible al alma racional. El spiritus adulterado en la sangre explicaba la supuesta estupidez de los nórdicos. Por contraste, el calor de los trópicos abría los poros de la piel, restando calor vital a la sangre, y de ahí la supuesta cobardía de los tropicales. La apertura de los poros, por otra parte, permitía la purificación de la sangre, con lo cual se refinaba el spiritus que permanecía en la sangre: de ahí el supuesto ingenio o perspicacia de los seres tropicales. Naturalmente, era la sangre en lugares templados como la Europa mediterránea la que supuestamente presentaba la temperatura y nivel de pureza correctos. De ahí la inteligencia y valentía que supuestamente habían caracterizado, primero, a los griegos, luego, a los romanos y, en una nueva era de expansión europea, por supuesto, a la nación castellana.

La distinción que establece Aristóteles entre europeos, asiáticos y griegos se la debe directamente a Platón, quien trata por boca de Sócrates en La República los atributos de la ciudad estado y del alma ordenada ${ }^{47}$. La República afirma que al alma humana la constituyen tres partes relacionadas jerárquicamente: el «raciocinio» (logismos), la «animosidad» (thumos) y el «apetito» (epithumia) ${ }^{48}$. El alma bien ordenada -aquélla en la cual el

\footnotetext{
46 Para una discusión de las cualidades de la sangre en la tradición aristotélica, ver Wey Gómez, 2008: 279-282. Se sigue allí a Alberto Magno, 1980: 26, líneas 62-74.

${ }^{47}$ La deuda de este fragmento de Aristóteles para con Platón me la sugirió originalmente el Profesor Alfonso Gómez-Lobo de Georgetown University.

48 Platón, 1991: 105-125. Sobre los términos logismos, thumos, y epithumia, ver Howland, 1993: 40. Sobre el carácter tripartita del alma, consultar Irwin, 1995: 203-222. También van Peursen, 1966: 34-49 y Murphy, 1951: 24-44.
} 
raciocinio se vale de la animosidad para gobernar sobre los apetitos o el instinto- es un alma que manifiesta sabiduría, valentía y templanza. Por implicación, el alma desordenada manifiesta frivolidad, cobardía e intemperancia. Sócrates incluso metaforiza las tres partes del alma como el hombre (la razón), el león (la valentía), y el monstruo de mil cabezas (la quimera). Si el hombre es incapaz de invocar al león para domar a este monstruo, será presa tanto del león como del monstruo. Sin sabiduría, valentía o templanza, el hombre no puede esperar actuar justamente, ni la ciudad dispensar la justicia a sus ciudadanos. El modelo geopolítico de Aristóteles les asignaba a los griegos la habilidad de realizar los dictados de la razón invocando la fuerza de voluntad para contravenir los efectos predatorios del instinto desenfrenado. Los bárbaros, por otra parte, eran incapaces de razonar adecuadamente o de invocar la fuerza de voluntad necesaria y, por tanto, para usar los términos de Platón, caían presas del león, de la quimera o de los dos. Este modelo, a pesar de su aparente simplicidad, le ha ofrecido al imperialismo occidental un raciocinio casi infalible: los colonizadores invariablemente justifican sus atropellos contra otros persuadiéndose a sí mismos de que aquéllos a quienes quieren controlar o exterminar carecen de la inteligencia o de la fuerza de voluntad para contrarrestar el caos suscitado por el instinto.

Este modelo le caía de perlas a Oviedo, quien en calidad de naturalista y de etnógrafo admiraría inmensamente la prodigalidad natural de las Indias y el enorme ingenio de sus gentes. Pero más tarde en la Historia general y natural de las Indias, en calidad de colono, administrador de la corona e historiador oficial, Oviedo habría de detallar todas «las fallas» de la naturaleza tropical que justificaban avasallar o esclavizar a los habitantes de las Américas: «esta gente», afirma Oviedo, «de su natural, es ociosa e viciosa, e de poco trabajo, e melancólicos, e cobardes, viles e mal inclinados, mentirosos e de poca memoria, e de ninguna constancia» ${ }^{49}$. Y España, a pesar de sus escandalosas ofensas en las Américas, no había de considerarse más que el látigo de Dios por «lo grandes y feos e inormes pecados e abominaciones destas gentes salvajes y bestiales». Así pues, la primera impresión de América en Europa como vasta extensión tropical desconocida para los antiguos le permitió a Oviedo inaugurar certidumbres paradójicas que, a mi parecer, laten al corazón de las obras naturales y morales de los siglos dieciséis y diecisiete, como también al corazón de las percepciones que nuestra propia cultura global posee del trópico.

\footnotetext{
${ }^{49}$ Fernández de Oviedo, 1991, vol. 1: 67.
} 


\section{BIBLIOGRAFÍA}

Adorno, Rolena, The Polemics of Possession in Spanish American Narrative, New Haven, CT, Yale University Press, 2007.

Adorno, Rolena, De Guancane a Macondo: Estudios de literatura hispanoamericana, Colección Iluminaciones 38, Sevilla, Renacimiento, 2008.

Alberto Magno, De natura loci, edición de Paul Hossfeld, 2 vols, tomo 4, partes 1 y 2 de Bernard Geyer (ed.), Alberti Magni opera omnia, Münster en Westfalia, Aschendorff, 1980.

Amador de los Ríos, José, "Vida y escritos de Gonzalo Fernández de Oviedo y Valdés", Historia general y natural de las Indias, de Gonzalo Fernández de Oviedo, Primera Parte, Madrid, Imprenta de la Real Academia de la Historia, 1851, vol. 1: ix-cvii.

Aristóteles, Politics, traducción de B. Jowett, J. Barnes (ed.), The Complete Works of Aristotle, 2 vols., Princeton, New Jersey, Princeton University Press, 1985, vol. 2: 1986-2129.

Averröes, Meteorologicorum, volumen 5 de Aristotelis opera cum Averrois commentariis, Venecia, Junctas, 1562, reproducción en facsímil, Frankfurt, Minerva, 1962.

Ballesteros Gaibrois, Manuel, Gonzalo Fernández de Oviedo, Madrid, Fundación Universitaria Española, 1981.

Baraibar, Álvaro, "Estudio preliminar", Gonzalo Fernández de Oviedo y Valdés, Sumario de la natural historia de las Indias (estudio, edición y notas de Álvaro Baraibar), Biblioteca Indiana 26, Madrid, Universidad de Navarra, Editorial Iberoamericana Vervuert, 2010: 7-59.

Carbia, Rómulo D., 1940, La crónica oficial de las Indias Occidentales, Buenos Aires, Ediciones Buenos Aires, 1940.

Carrillo Castillo, Jesús, "Naming Difference: The Politics of Naming in Fernández de Oviedo's Historia general y natural de las Indias", Science in Context, XVI/4 (Cambridge, UK, 2003): 489-504.

Carrillo Castillo, Jesús, Naturaleza e imperio: La representación del mundo natural en la "Historia general y natural de las Indias" de Gonzalo Fernández de Oviedo, Aranjuez, Ediciones Doce Calles, 2004.

Fernández de Oviedo y Valdés, Gonzalo, Historia general y natural de las Indias, edición y estudio preliminar de Juan Pérez de Tudela Bueso, 5 vols., Sevilla, Biblioteca de Autores Españoles, 1991.

Fernández de Oviedo y Valdés, Gonzalo, Sumario de la natural historia de las Indias (estudio, edición y notas de Álvaro Baraibar), Biblioteca Indiana 26, Madrid, Universidad de Navarra, Editorial Iberoamericana Vervuert, 2010/1526. 
Gerbi, Antonello, Nature in the New World: From Christopher Columbus to Gonzalo Fernández de Oviedo, Jeremy Boyle (trad.), Pittsbugh, Pennsylvania, University Press, 1985 [1975].

Hanke, Lewis, Aristotle and the American Indians: A Study in Race Prejudice in the Modern World, Londres, Hollis and Carter, 1959.

Hipócrates, Airs, Waters, Places, W. H. S. Jones (ed. y trad.), Hippocrates, Loeb Classical Library, Cambridge, Massachusetts, Harvard University Press, 1984: 65-137.

Howland, Jacob, The Republic: The Odyssey of Philosophy, Nueva York, Tawyne Publishers, 1993.

Irwin, Terence, Plato's Ethics, Nueva York, Oxford University Press, 1995.

Lloyd, G. E. R. "The Hot and the Cold, the Dry and the Wet in Greek Philosophy", The Journal of Hellenic Studies, LXXXIV (Cambridge, UK, 1964): 92-106.

Merrim, Stephanie, “The Apprehension of the New in Nature and Culture: Fernández de Oviedo's Sumario", René Jara y Nicholas Spadaccini (eds.), 1492-1992: Re/ discovering Colonial Writing, número especial de Hispanic Studies, IV (Minneapolis, MN, 1989): 165-199.

Murphy, N. R., The Interpretation of Plato’s “Republic”, Oxford, Clarendon Press, 1951.

Myers, Kathleen Ann, Fernández de Oviedo's Chronicle of America: A New History for a New World, Nina M. Scott (trad.), Austin, Texas, University of Texas Press, 2007.

Paden, Jeremy, "The Iguana and the Barrel of Mud: Memory, Natural History, and Hermeneutics in Oviedo's Sumario de la natural historia de las Indias", Colonial Latin American Review, XVI/2 (Nueva York, NY, 2007): 203-226.

Pagden, Anthony, The Fall of Natural Man: The American Indian and the Origins of Comparative Ethnology, Cambridge, Cambridge University Press, 1982.

Platón, The Republic of Plato, Alan Bloom (trad. y ed.), 2a ed., Nueva York, Basic Books, 1991.

Pérez de Tudela y Bueso, Juan, "Vida y escritos de Gonzalo Fernández de Oviedo", Gonzalo Fernández de Oviedo, Historia general y natural de las Indias, Juan Pérez de Tudela (ed.) Madrid, Biblioteca de Autores Españoles, 1991 [1959], vol. 1: vii-cLXXv.

Plinio, Cayo Plinio Segundo, Natural History, H. Rackham et al. (trad.), Loeb Classical Library 330, 352, 353, 370, 371, 392-394, 418, 419, 10 vols., Cambridge, Massachusetts, Harvard University Press, 1938-1963.

Prieto, Andrés I., "Classification, Memory, and Subjectivity in Gonzalo Fernández de Oviedo's Sumario de la natural historia (1526)", Modern Language Notes CXXIV/2 (Baltimore, MD, 2009): 329-349. 
Saco, José Antonio, "Apéndice a La esclavitud de los Indios en el Nuevo Mundo", Revista de Cuba, XIII (La Habana, 1883): 167-176.

Sánchez Jiménez, Antonio, "Memoria y utilidad en el Sumario de la natural historia de las Indias de Gonzalo Fernández de Oviedo", Colonial Latin American Review, XIII/2 (Nueva York, NY, 2004): 263-273.

Turner, E. Daymond, "Los libros del alcaide: la biblioteca de Gonzalo Fernández de Oviedo y Valdés", Revista de Indias, XXXI (Madrid, 1971): 139-198.

Van Peursen, C. A., Body, Soul, Spirit: A Survey of the Body-Mind Problem, Londres, Oxford University Press, 1966.

Wey Gómez, Nicolás, The Tropics of Empire: Why Columbus Sailed South to the Indies, Cambridge, Massachusetts, The MIT Press, 2008.

Fecha de recepción: 2 de junio de 2011.

Fecha de aceptación: 17 de febrero de 2012.

\section{Memoirs of the Torrid Zone: Classical Naturalism and America's Tropicality in Gonzalo Fernández de Oviedo's Summary of the Natural History of the Indies (1526)}

This essay examines the role of tropicality in the taxonomy of Amerindian nature and culture offered by Oviedo's Summary of the Natural History of the Indies (1526). Pointing to the scientific and technical paradigms that inform this treatise, the author argues that the construal of the West Indies as a «tropical» place -distinct from Mediterranean Europe, yet similar to the East Indies-offers Oviedo a fundamental framework for conveying America's complex alterity and for tackling a geopolitical debate over the legitimacy of the conquest.

KEY WORDS: America; natural history; ethnography; zoology; botany; mineralogy; theory of the five zones; torrid zone.

Revista de Indias, 2013, vol. LXXIII, n. ${ }^{\circ} 259$, 609-632, ISSN: 0034-8341

doi:10.3989/revindias.2013.20 